\title{
Thin Ice: Teasing Play as a Network-Forming Force in Organizations
}

\author{
RITA TÓTH* \\ *Corvinus University of Budapest, Institute of Management; \\ toth.rita@uni-corvinus.hu
}

DOI: $10.14267 / 978-963-503-867-1 \_09$

\begin{abstract}
Play is a deeply human constitutive activity of organizational life, which may manifest in several distinct processes. In the present study, the author compasses a particular culturally relative form of play, namely teasing in the workplace setting. Conducting a meta-synthesis of adjacent streams of literature, the author reframes the concept of teasing and inspects it through the analytical lens of play. The research unfolds how teasing behaviour may form an invisible meta-network in organizations, which may fundamentally affect group and organizational dynamics.
\end{abstract}

Keywords: play at work, teasing, serious play, network of play

Funding: The present publication is the outcome of the project „From Talent to Young Researcher project aimed at activities supporting the research career model in higher education," identifier EFOP-3.6.3-VEKOP-16-2017-00007 co-supported by the European Union, Hungary, and the European Social Fund. 


\section{Introduction}

Play, as a core process of organizing, is getting increasing attention among organization scholars and practitioners lately, as it is studied as an alternative form of knowledge production, knowledge-sharing, and learning. In the workplace context, scholars have already revealed how play enhances creativity (Mainemelis \& Ronson, 2006), makes decision-making more flexible and helps relating to unknown future (Andersen \& Pors, 2014, 2015), develops norms and ethical orientation (Statler et al, 2009) and supports the well-being of the employees (Costea et al., 2005). Still, workplace play is blurred with gamification efforts, playful design or top-down management practices neglecting the fact that what is said to be a game or a play activity is not always the same as what is perceived as play for real from the participants' perspectives. As part of a broader research in 2020, which aimed to shed light on the employee's perceptions and recognitions of workplace play, participants were asked to complete the following unfinished sentence: „The best game/type of play at my workplace is...." Amongst others, the activity of teasing has emerged significantly, labelled as play. These results suggested having a close look at teasing in the organizational settings and examine the phenomenon through the lens of play.

Reframing the already ambiguously playful phenomenon of teasing as play, may lead us towards new theoretical knowledge and practical implications. Research that unfolds the characteristics of teasing and play relationships in organizations is scarce. Hence, it is worth asking the question as to how can we imagine organizations as a set of play processes and how can we understand teasing within this setting? In this conceptual study, I look for answers for this question, and I build on interdisciplinary knowledge about teasing and play theories. The aim of the research is to synthesize existing knowledge and come to a new awareness of teasing play as an underlying effect of organizational dynamics. As for my main argumentation I propose, that teasing play is a call for meta-level relationships and gives rise to the emergence of a social meta-network in organizations, which has a significant impact on group and organizational dynamics.

\section{Methodology}

Noting that both play and teasing are understudied and under-published fields in management studies, I have carried out a meta-synthesis exploring also adjacent streams of literature. Meta-synthesis is an interpretative method to explore selected qualitative research (Thorne et al., 2004; Major \& Savin-Binden, 2011). The present meta-synthesis pertains to the constructionist category according to the typology of Major and SavinBaden (2011), as the analysis and the synthesis of data was followed by interpretation 
and construction of new meanings of existing qualitative evidence. Towards this end, I start with the review of the concept of play, as it has been understood in the literature of management studies, and continue the review of knowledge about teasing. Throughout a theory-building exercise, I conceptualize teasing as a culturally relative form of play in organizations. I argue that the interaction of teasing play is the trigger, which calls certain relations into existence and further determine their quality as positive, negative or play.

\section{Theoretical findings}

\section{Play at work. Two sides of the same coin}

Even though developmental psychology traces play until the age of adolescence, there is evidence, that play is peculiar to adulthood as well. Hence, it can be considered as a lifelong fundamental characteristic of human being, constantly influencing our milieu even in organizational settings. Some researchers argue that play is the most understudied and least understood form of organizational behaviour (Mainemelis \& Ronson, 2006). The forerunner theoretical basis of the ongoing "ludicization" process of Western society, in the course of which social, cultural and economic life is becoming growingly play-orientated (Thibault \& Heljakka, 2018), comprises the theory of an entirely play-based culture (Huizinga, 1944), the assumption of the everyday role-playing of humans (Goffmann, 2008) and the anthropological information about rites and ritual (Turner, 1982). Although it is easily recognizable by anyone as a human activity, the boundaries of play remain unclear.

In the workplace context, there is no consensus-based scientific definition neither of play nor of games. General play theories emphasise the autotelic, joyful nature of play and refer to the spatial and temporal characteristics, according to which play usually happens independently from and parallel to real time and owns its own virtual space in a rather spiritual sense. Regarding the immature concept of organizational play, it is a common agreement that play is a multifaceted metacommunicative activity (Bateson, 1987) that is carried out for the purpose of amusement and fun, approached with an enthusiastic and in-the-moment attitude, and it is highly interactive (VanFleet \& Feeney, 2015). Play can be as much as the mode of learning or knowing as the condition of emotional survival (Sutton-Smith, 2008). However, there are still major differences in the conceptualization of workplace play regarding the paradigm lens through which it is studied.

From a functionalist perspective, play in the organizational context is seen as an instrument, which may be an activity, a process, a trait or a cultural feature originating from work or non-work-related antecedents holding a number of roles depending on its 
character and resulting in various outcomes on individual, team and organisational level (Petelicz et al. 2018). The approach constitutes management techniques and developmental practices as well under the emerging umbrella terms of serious play (Statler et al., 2009) and serious games (Mayer et al., 2016). On one hand, serious games make up the digital and traditional games that have been created to develop a relevant workplace competence (Mayer et al., 2016). On the other hand, the relevance of serious play has been approached from the stance of leadership development and organizational development in terms of utilizing the imaginative nature of playful tasks to construct reallife solutions in the context of strategic thinking, innovation or moral development (Statler et al., 2011). Statler et al. (2011) reframed serious play as practice of paradox, and argued that the paradox of intentionality, namely that play, which is carried out for play itself, can serve other ends, may support the stretching of the boundaries of people.

However, there is more to play than just considering it as a tool for management and development. Play goes beyond managing due to its inherently ambiguous and open-ended nature. Considering philosophical thoughts within the frame of an interdisciplinary approach, we find that play refers to the ontology of the entire human existence beyond matters of childhood. In this sense, playfulness is a fundamental characteristic of organizations, which reframes our understanding of workplace processes, meaning thatall kinds of activities can be perceived and experienced as play (Roy, 1959; Salovaara \& Statler 2018). From the reverse side, all kinds of activities can be recognized as play, based on subjective interpretation. Play, therefore, permeates organizational life and gives an intrinsically motivated, joyful nature for the activities, from the perspective of the actors.

Andersen and Pors (2014) argue that play is the possibility for organizations to reach out for presently imaginable futures, when implicated into management practises. Their propositions are based on empirical research on the comparison of temporalities of play and decision-making. Hence, decisions bring uncertainty of the future to the present, and conversely play brings the present into the future, creating a surplus of possibilities, thus, expanding contingency while taking advantage of it (Andersen \& Pors, 2014). Through this lens, the role of play is to enhance the transformative capability of an organization by preparing for continual change and development. By making available opportunities visible through play, a "shadow organization" evolves (Andersen, 2009) and reality doubles. In this sense an organization can be considered as a set of constantly negotiated social constructs (Schwandt, 2000), which can be created into meaningful existence by play (Andersen, 2009). 


\section{Teasing}

To better understand the phenomenon, there is an ongoing research tradition, which frames teasing with the help of Erving Goffman's concept of face (1955). Researchers engaged towards this approach consider teasing as a form of context-dependent strategic interaction, which varies along the participants face-concerns (Haugh, 2010; Keltner et al., 2001) and occur to renegotiate conflicts and regulate norm deviations (Keltner et al., 2001). Such framing gave rise to an unlimited number of hypothesises and studied the correlation between social distance, social power, and teasing-related variables such as aggression, likelihood, or the quantity of playful markers (Keltner et al., 1998, 2001). However, lacking a consensus-based definition and appropriate methodology, these studies remained unproved assumptions.

A related line of argument presents teasing as a form of conversational joking, serving as a means to social regulation (Fine \& Saucey, 2005), individual, social and relational identity construction and display (Boxer \& Cortez-Condé, 1997; Schnurr, 2009), workplace initiation (Mawritz et al., 2020) and emotional attunement (Pouthier, 2017). Although researchers, who studied humour and joking in the organizational context, have already shown how these activities may be indicators of paradox and ambiguity (Hatch, 1993) or resistance (Westwood, 2013), there has been little attention paid on what the particular teasing habits would tell about organizations and how this knowledge could be implemented into organization theory or organizing practice.

In the present paper, I build my conception on the definition of Keltner et al. (2001), which distinguishes teasing from other relating activities and clarifies its conceptual place in humorous settings. Teasing may seem like disgraceful mocking on the surface, therefore, it is easily related to hazing and bullying instead of play. After reviewing and synthesizing more than 50 papers about teasing, Keltner et al. (2001) have created a definition for teasing, which overcomes the blind spots of its antecedents. With their words, a tease is an "intentional provocation accompanied by playful off-record markers that together comment on something relevant to the target" (Keltner et al., 2001, 234 p.). This definition highlights the intentional nature of the provocation, which is not labelled neither as inherently kind-hearted nor malignant. In this sense, teasing instead is inherently ambiguous and its outcomes depend on the interplay between the parties including the response given to a tease (Alberts, 1992). Responses, however, show correlation with the perception of the intentionality of teasing, which is mediated by the feeling of closeness (Gorman \& Jordan, 2015). Keltner's definition clearly distinguishes teasing from other associated aggressive activities (e.g., bullying) which do not include playful off-record markers. 


\section{Teasing play in organizations: A theory building exercise}

What if we imagine the inherently playful teasing as it was play? What impact would it have on organizations? Invoking the teasing continuum of Boxer and Cortez-Condé (1997), which ranges from bonding to nipping to biting, we should note the underlying play theory of Bateson (1987) who argued that "a playful nip denotes a bite, but it does not denote what would be denoted by a bite" (1987, 18 p.). He emphasized, that as in the animal world, there is a safe space for practising fighting, when they engage in play and there is such a specific virtual place for people who play as well. In this sense, a tease is a kind of initiation that has transformative ability by shocking or surprising the participant, thus arming him or her with resilience and vigilance for the future, theoretically serving as the condition for emotional survival (Sutton-Smith, 2008). Play creates a "magic circle" as its own space, where its own specific rules obtain (Huizinga, 2016). The magic circle is a virtual world in a spiritual sense, but it can be created also in a digital environment. This "magic circle" or "shadow organization", which is the doubling of the real world, can be understood as the liminal space in terms of rituals, where transformation happens.

Second, as play is considered to be an activity, complemented by a meta-communication process, which constantly revises whether the activity was play (Bateson, 1987), a tease can be considered as an upbeat, an invitation to expand the relationship onto a higher, more intimate level (Haugh \& Pillet-Shore, 2017). The invitation can be accepted or declined as well, which means, that through teasing play, a social meta-network emerges in organizations, which is beyond formal control. Tie as the fundamental unit of social network analysis can be distinguished along the typology of dyadic relations as shown in Table 1. (Borgatti et al., 2009). In the case of the teasing play network, relational distinctions can be assumed as follows. 
Figure 1: Dyadic relations of the teasing play network

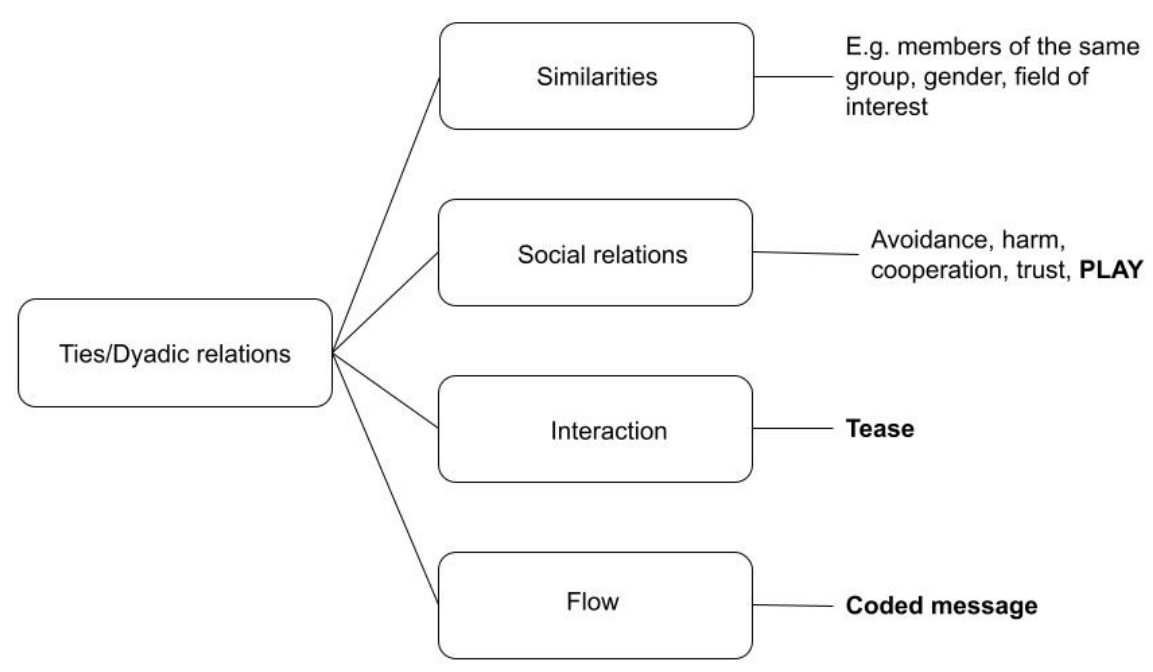

Source: adapted from Borgatti et al. (2009)

Building on the dyadic relations model, a tease can be considered as an interaction, which may serve as the trigger, or initiative of the new level of the relationship. This new level can be described either as positive or as negative as the result of the answer given to the tease. More clearly, during the interaction of teasing, a coded message flows from the teaser to the target and the coding of the message determines the further social quality of the tie. In this sense, a tease may result in distrust or avoidance which count as negative relations, and it can also end up in a trustful or a cooperative relation. Here I add the play relation as a third, paradox possibility, standing beyond positive or negative judgement, still characterised by a transformative quality.

Within this meta-network, a special focus should be given to the interaction of the teasing play as it forms the social relation as a one-time interaction and furthermore constantly reforms the relation when conducted regularly. If the tease triggers a play relation, the characteristics of the tie will depend on which rhetoric of play is dominating it. There are seven overlapping rhetorics of play identified as power, self, identity, progress, fate, imaginary and frivolity, which may determine how we see and study the phenomenon, and also the meaning or function we appropriate to it (Sutton-Smith, 1997). In other words, relationships of this meta-network may be a means to distinct ends, which are associated with a particular rhetoric. In this regard a teasing relationship can head 
towards creative outputs or norm regulation as well as counter-productive status maintenance.

All things considered if we build on the seminal theory of Huizinga (2016), who put the whole human culture on a play basis, we might be empowered to "read" the play behaviour including teasing patterns of organizations to understand organizational culture in a given setting. Geertz's idea (2017) about social play being a projective platform from which power relations can be read, suggests that the inspection of play might be a supportive ground for organizational development (OD) practices, as well as critical management studies.

\section{Conclusion and implication for further research}

I briefly summarized existing knowledge and theories about teasing and play in a workplace context and introduced my conceptualization of teasing as a particular kind of workplace play. By doing so, I came to a new awareness of teasing play as a networkforming force in organizations, which can be analysed in terms of play, constituting paradox intentionality, liminal transformations and underlying play rhetoric, which may fundamentally affect organizational dynamics.

My contribution to the existing scientific literature is twofold. On one hand, by reframing teasing as play I opened new doors for further understanding complex social phenomena in group and organization behaviour. On the other hand, by revealing how teasing behaviour may form a meta-level network, my study may serve as a point of departure when advancing knowledge on how certain ties come into existence while others disappear in organizations.

A limitation of the research is that the conduct of this meta-synthesis was influenced by my own experience and interest in the topic of teasing. Another limitation is concerning the methodology, as there are a number of high-quality studies excluded from this investigation, even though quality and theoretical saturation is more important than numbers for this kind of meta-synthesis. However, bearing these limitations in mind, I argue that my conceptual study could add something to the better understanding of teasing play at work and provided some initiatives for further research. Given that the domains of teasing and play represent a relatively under-explored field of research, there are many new and exciting questions, which would be important to pursue regarding the themes along which organizational play can be analysed, and methodological concerns for identifying teasing networks in organizations. 


\section{References}

Alberts, J. K. (1992). An Inferential/Strategic Explanation for the Social Organisation of Teases. Journal of Language and Social Psychology, 11(3), 153-177. https://doi.org/10.1177/0261927x92113003

Andersen, N. A, \& Pors, J. G. (2014). Playful membership: Embracing an unknown future. Management \&3 Organizational History, 9(2), 166-183. https://doi.org/10.1080/17449359.2014.891796

Andersen, N. A. (2009). Power at play: The relationships between play, work and governance. Palgrave Macmillan.

Bateson, G. (1987). Steps to an ecology of mind. Northvale, NJ: Jason Aronson.

Borgatti, S. P., Mehra, A., Brass, D. J., \& Labianca, G. (2009). Network Analysis in the Social Sciences. Science, 323(5916), 892-895. https://doi.org/10.1126/science.1165821

Fine, G. A., \& Soucey, M. D. (2005). Joking cultures: Humor themes as social regulation in group life. Humor - International Journal of Humor Research, 18(1), 1-22. https://doi.org/10.1515/humr.2005.18.1.1

Geertz, C. (2017). The interpretation of cultures. London: Basic Books. (Original work published 1971)

Goffman, E. (1955). On face work: An analysis of ritual elements in social interaction. Psychiatry, 18(8), 213-31.

Goffman, E. (2008). The presentation of self in everyday life. New York: Anchor Books. (Original work published 1959)

Gorman, G., \& Jordan, C. H. (2015). "I know you're kidding": Relationship closeness enhances positive perceptions of teasing. Personal Relationships, 22(2), 173-187. https://doi.org/10.1111/pere.12071

Hatch, M. J., \& Erhlich, S. B. (1993). Spontaneous Humour as an Indicator of Paradox and Ambiguity in Organizations. Organization Studies, 14(4), 505-526. https://doi.org/10.1177/017084069301400403

Haugh, M. (2010). Jocular mockery, (dis)affiliation, and face. Journal of Pragmatics, 42(8), 2106-2119. https://doi.org/10.1016/j.pragma.2009.12.018

Haugh, M., \& Pillet-Shore, D. (2017). Getting to know you: Teasing as an invitation to intimacy in initial interactions. Discourse Studies, 20(2), 246-269. https://doi.org/10.1177/1461445617734936

Huizinga, J. (1944). Homo ludens: A study of the play-element in culture. Kettering, OH: Angelico Press.

Keltner, D., Capps, L., Kring, A. M., Young, R. C., \& Heerey, E. A. (2001). Just teasing: A conceptual analysis and empirical review. Psychological Bulletin, 127(2), 229-248. https://doi.org/10.1037/0033-2909.127.2.229

Keltner, D., Young, R. C., Heerey, E. A., Oemig, C., \& Monarch, N. D. (1998). Teasing in hierarchical and intimate relations. Journal of Personality and Social Psychology, 75(5), 1231-1247. https://doi.org/10.1037/0022-3514.75.5.1231 
Mainemelis, C., \& Ronson, S. (2006). Ideas are Born in Fields of Play: Towards a Theory of Play and Creativity in Organizational Settings. Research in Organizational Behavior, 27, 81-131. https://doi.org/10.1016/s0191-3085(06)27003-5

Major, C. H., \& Savin-Baden, M. (2011). Integration of qualitative evidence: Towards construction of academic knowledge in social science and professional fields. Qualitative Research, 11(6), 645-663. https://doi.org/10.1177/1468794111413367

Mawritz, M. B., Capitano, J., Greenbaum, R. L., Bonner, J. M., \& Kim, J. (2020). Development and validation of the workplace hazing scale. Human Relations, 001872672095705. https://doi.org/10.1177/0018726720957058

Petelczyc, C. A., Capezio, A., Wang, L., Restubog, S. L., \& Aquino, K. (2018). Play at Work: An Integrative Review and Agenda for Future Research. Journal of Management, 44(1), 161-190. https://doi.org/10.1177/0149206317731519

Pouthier, V. (2017). Griping and Joking as Identification Rituals and Tools for Engagement in Cross-Boundary Team Meetings. Organization Studies, 38(6), 753-774. https://doi.org/10.1177/0170840616685358

Roy, D. (1959). "Banana Time": Job Satisfaction and Informal Interaction. Human Organization, 18(4), 158-168. https://doi.org/10.17730/humo.18.4.07j88hr1p4074605

Schnurr, S. (2009). Constructing leader identities through teasing at work. Journal of Pragmatics, 41(6), 1125-1138. https://doi.org/10.1016/j.pragma.2008.10.002

Statler, M., Heracleous, L., \& Jacobs, C. D. (2011). Serious Play as a Practice of Paradox. The Journal of Applied Behavioral Science, 47(2), 236-256. https://doi.org/10.1177/0021886311398453

Statler, M., Roos, J., \& Victor, B. (2009). Ain't Misbehavin': Taking Play Seriously in Organizations. Journal of Change Management, 9(1), 87-107. https://doi.org/10.1080/14697010902727252

Sutton-Smith B (2008) Play theory: A personal journey and new thoughts. American Journal of Play, 1:80-123.

Sutton-Smith, B. (1997). The ambiguity of play. Cambridge, MA: Harvard University Press.

Thorne, S., Jensen, L., Kearney, M. H., Noblit, G., \& Sandelowski, M. (2004). Qualitative Metasynthesis: Reflections on Methodological Orientation and Ideological Agenda. Qualitative Health Research, 14(10), 1342-1365. https://doi.org/10.1177/1049732304269888

Turner, V. W. (1982). From ritual to theatre: The human seriousness of play. New York: PAJ. Westwood, R. I., \& Johnston, A. (2013). Humor in organization: From function to resistance. Humor, 26(2). https://doi.org/10.1515/humor-2013-0024 